\title{
Older people and their care partners' experiences of living with mental health needs: A focus on collaboration and cooperation
}

\author{
Brendan McCormack ${ }^{1}{ }^{*}$ and Astrid Skatvedt ${ }^{2}$
}

${ }^{1}$ Brendan McCormack, DPhil, RGN, RMN, Head, Professor, Division of Nursing, Queen Margaret University Edinburgh, Edinburgh, UK; Professor II, University College of South-East Norway, Drammen, Norway, Professor of Nursing, Maribor University, Maribor, Slovenia, Extraordinary Professor, University of Pretoria, Pretoria, South Africa, and Visiting Professor, Ulster University, Ulster, UK;

${ }^{2}$ Astrid Skatvedt, PhD, Researcher, National Advisory Unit on Substance Use Disorder Treatment, Oslo, Norway

*Correspondence: Brendan McCormack, Professor, Division of Nursing, School of Health Sciences, Queen Margaret University, Musselburgh, East Lothian, Edinburgh EH21 6UU, UK. Telephone:+44 0131474 0000 .

E-mail: bmccormack@qmu.ac.uk

Twitter: @profbrendan

\section{ABSTRACT}

Aim To explore how older people living at home with mental health needs and their care partners experienced the practices of collaboration within and between services.

Background Many health care strategies for community mental health services for older people espouse a person-centred approach or principles that are similar in focus.

Design This paper reports on the first stage of a 3-year action research project that focused on improving mental health services for older people and their care partners living at home. Data were collected through individual interviews. Twenty people were interviewed. Data were analysed continuously and in parallel with data collection for the identification of themes. We focus on two particular themes, 'acknowledgement, recognition and respect' and 'the prestige hierarchy of mental illness in older people'.

Results We adopt a microsociological approach to the analysis of these themes, with a particular focus on 'interaction ritual chains' (IRC) and threshold theory. We highlight how older people and their care partners experience discontinuities in their everyday interactions with nurses and care workers and that this impacts on their experience of person-centred care.

Conclusions Older people with mental health needs and their care partners need high levels of energy to express their needs and have them met in a way that reflects principles of partnership working.

Implications for Practice: Nurses and care workers need to consider how 'tasks' can be used as a vehicle for creating emotional connections with service users. Service managers and leaders need to consider the implications of discontinuities in care on service user, care partner, nurses and care workers experiences. 


\section{Keywords}

collaboration, ethnography, mental health, gerontology, older people, nursing practice

\section{What does this paper contribute to the wider global clinical community?}

- This paper provides further insight from a sociological perspective of the importance of emotional engagement in nurse/care worker relationships.

- The research demonstrates how emotional engagement can create a 'chain of connection' that has a positive effect on the mental health of older people and their care partners.

\section{INTRODUCTION}

Mental health services policy and practice for older people living in the community continues to be a developmental issue in many countries. There are a variety of reasons for this variation, including the model of care delivery, the integration (or not) of services, assessment structures and processes, diagnostic priorities and professional role boundaries. Whilst there is no standard approach to the delivery of mental health services for older people in their own homes, the availability of comprehensive mental health services is critical to the well being of older people and their ability to live independent lives.

In this paper we present the findings of a project that sought the perspectives of older people and their care partners regarding their experiences of collaboration and cooperation with municipal health services regarding their mental health needs. The project reported here is the first stage of a 3-year action research project that focused on older people and support for their mental health needs in a particular Municipality (local government district) in Norway. The findings highlighted the interrelationship between systems, processes and people in the effective delivery of health services to older people with mental health needs. However, in this paper we focus on two particular key themes, 'acknowledgement, recognition and respect' and 'the prestige hierarchy of mental illness in older people' (after Album \& Westin 2008). 


\section{BACKGROUND}

Adult mental health services are in a period of rapid development seeking to expand noninstitutional mental health care for people with mental health needs. In line with the World Health Organization (2015) and European Commission (2008) policy, models of community care are being established with the objective of maximising access to care and rehabilitation services. However, the majority of mental health policies and strategies focus on the adult population below retirement age and do not take adequate account of the needs of older people. In Norway, the final evaluation of the National Action Plan for Mental Health (Norwegian research Council 2009) reveals that while adults with mental illness and children and adolescents have been given priority, older people with mental health needs have been overlooked.

According to the WHO, over $20 \%$ of adults aged 60 and over live with a mental illness, with depression being one of the most common illnesses experienced. Anxiety disorders affect $3.8 \%$ of the population of older people globally, and around a quarter of deaths from selfharm are among those aged 60 years or above. Substance abuse problems among older people are often overlooked or misdiagnosed (WHO 2015 i). Mental health problems are under-identified by health-care professionals and older people themselves, and the stigma surrounding mental illness makes people reluctant to seek help. One explanation could be that these symptoms are accepted as a normal feature of ageing. However, Lightbody et al. (2007) claim that health care professionals may lack knowledge in recognising depression. In addition efficiency demands and lack of time can be a part of the situation, even though older people with mental health problems show the same treatment response as younger persons (Lenze et al 2005). Suicide among older people is a rising phenomenon globally (Shah 2007), but is rarely addressed (Kjølseth 2009). Men 70+ seem to be at specific risk of suicide. Older people can also experience psychosis, either following dementia, severe depression or associated with acute physical illness. Currently there are about 66000 
persons with dementia in Norway. About 10000 new persons are affected annually and about every fifth person living with dementia is in need of care during the last years of their lives (Helse-og omsorgsdepartementet 2007). There are large numbers of older people living at home with a variety of mental health problems, who need good quality treatment and support to enable them, and their family members, to have the best possible quality of life.

In Norway, health services reform is focused on strengthening such treatment and support to people at home. The Coordination Reform (Helse- og omsorgsdepartementet 2008-2009). has a focus on strengthening service users' participation and collaboration in service developments.. Collaboration is founded in human relationships, developing dialogues and working in partnerships (Strong et al 2011). As we see it, the principles underpinning The Coordination Reform strategy are consistent with person-centred values and principles. Internationally health strategy developments in recent years have highlighted the importance of more personcentred and recovery based approaches (Hill et al 2010). In mental health care (Borg et al 2009 I \& ii), as well as in the care of older people, policy and practice developments have emphasised this through a variety of terms, strategies and training programs. The essence of person-centred practice is that of collaboration between service users and care providers, as well as collaboration between care providers. It has been argued that without an explicit commitment to collaboration and engagement between care providers, then person-centred (collaborative) practice cannot exist with service users (McCormack \& McCance 2010; McCormack et al 2009; McCormack et al 2010). The principles underpinning person-centred practice can be summarised as being concerned with: treating people as individuals; respecting their rights as a person; building mutual trust and understanding, and developing collaborative relationships. However, translating the core concepts of person-centred practice into every day work is challenging (McCormack \& McCance 2010; McCormack et al 2009). The reasons for this come in many forms and are often indicative of the context in which care is being delivered, including 
the demands of translating policy initiatives into practice (Biong \& Svensson 2009), organisational culture (Napier et al 2014), attitudes of clinicians (McCormack and McCance 2010), professional-service user relationships (Borg et al 2010) and the demands placed on service-users to navigate complex healthcare systems (Laird et al 2015). McCormack et al. (2010) undertook a meta-synthesis of person-centredness and its discourse in the international literature. They concluded that thus far, approaches to the development of person-centredness have adopted a separatist and competing position and lack an interdisciplinary multi-focus approach.

\section{METHODS}

\section{Research Aim}

The aim of the research reported in this article was to explore how older people living at home with mental health needs and their care partners experienced the practices of collaboration within and between services.

\section{Study Setting}

The study was undertaken in a rural municipality in the South Eastern part of Norway. This municipality has a population of nearly 23000 people. General services for the older population are organised in the Health and Care Division, with one manager and six teams led by submanagers. Local based Mental Health, supported housing and day/activity centers, as well as individual follow-up are organised in two other teams led by different sub-managers. Coordinating and collaborating with older people living at home with a variety of mental health problems is identified as particularly challenging. In 2010 the Mental Health Division gave services to 234 persons, and received 132 new applications. Approximately $10 \%$ of the service users and the persons seeking services were older than 65 years of age. The Mental Health Division provided service to 4 persons older than 65 in 2014, whilst the Home Care Service gave care to 420 persons, where approx. 45 had mental health needs 


\section{Ethics}

Ethical approval for the project was secured from the Norwegian Social Science Data Services (Approval number 242181). The Principal Investigator (PI) and other members of the research team had extensive experience of engaging in similar research and were experienced in managing ethical issues that may arise. All data were anonymised so as to not expose any personal details of narrators. In the feedback of data, extracts of data only were fed back and so whole narratives were not seen by anyone other than the researchers. All data were stored on personal computers in password-protected files and were only accessed by members of the research team.

\section{Methods and Sample}

A convenience sample of 25 older people with mental health needs and 25 family members/care partners was considered to be an appropriate sample to participate in a $1: 1$ interview. It was intended that these older people and care partners would be identified by members of staff of the home care service and the mental health team in the municipality. However, initial discussions with the staff in both care service identified that achieving this size of sample would be challenging for several reasons. First and foremost the staff in the home care service lacked time to collect voluntary informed consent during their daily work. Further, they had not received enough information about the participation in the project from the municipal leadership, and finally they were not always clear which clients they attended had a diagnosed mental health problem. We also identified in the early stages of the study that the staff viewed the support of the researchers in the identification of potential participants as 'yet another thing to do' in an already burdensome workload. For the part of the mental health team, it became clear that they had few older persons as patients, and therefore also few to recruit as participants in the study. As a result, potential interviewees were mainly contacted by one of the research team (AS) during accompanied visits with staff from the Home Care Services team, and invited to participate. As potential interviewees were approached, it became clear that 
some did not consider themselves to have a mental health problem or if they were aware, did not want to be interviewed about it.

Care partners were even more reluctant to participate. There may be several reasons for this. One is that care partners found participation meaningless or insignificant, due to a lack of hope for changes to happen. Another is that care partners' felt bad about talking of burdens associated with their situation as care partner to a loved one with mental health problems - for some of them almost for a lifetime. We also experienced that some of the care partners did not wish to participate as they feared that talking about caring issues provoked anxiety regarding issues that they has 'hidden away' for many years.

The focus of the interviews was the participants' understandings of person-centred mental health care and how they had experienced the services they were provided. Drawing on the international literature on person-centred practice and in collaboration with service users who were members of 'the competence group' (group of persons with experience of mental health services who act as advisors to the project), a semi-structured interview schedule was developed. The interview was unstructured with one lead question inviting the participants to talk about their experiences of engaging with services that provided care and support to them. In the end 20 people were interviewed - 16 older people with mental health care needs $(11$ women and 5 men) and 5 care partners ( 1 woman and 4 men).

\section{Data Analysis}

Data for this stage of the research project were analysed continuously and in parallel with data collection. The analysis had an inductive approach when it comes to identifying themes (Patton 1990). Firstly, patterns were made visible through a detailed reading of transcribed interviews and field notes maintained in connection with the interviews. These data were reviewed repeatedly in order to identify patterns. Then, situations and phenomena that emerged as 
significant were noted and coded. These codes were then combined to create themes. The intention was to present thick descriptions (Geertz 1973) of the data.

\section{FINDINGS}

The findings identified a range of interrelated issues that impacted on collaboration and cooperation in the delivery of mental health services to older people and that ultimately impacted on older persons' experiences of person-centred services. These fall into two major themes - 1) Acknowledgement, recognition and respect; 2) The 'Prestige Hierarchy' of mental illness. In the presentation of findings, all data have been anonymised. In quotations the letter 'I' refers to the interviewer, 'SU - service user and CP - care partner'.

\section{Acknowledgement, Recognition and Respect}

The need for service users and their care partners to be acknowledged, recognised and respected by the different teams, at different levels in the teams and across the organisation of services, was very important to their experiences of health services:

I: // what kind of contact you have with, or cooperation you have with the municipality, that is Home Care or other stuff like that?

SU: I don't have any cooperation with them.

I: You have no cooperation?

SU: No! They don't give a shit about me. $\quad$ (B11; service user - female)

Another female participant was not allowed to administer her medication (neuroleptics) herself, due to her being a suicide risk. The home care nurses came to her home in order to monitor her taking her pills: "they just give me the pills, then they run off again /.../". 
This sense that the healthcare teams or individual care workers in teams seemingly didn't care about the person needing care, was echoed by other service users and care partners too:

CP: But then he was supposed to come home [to the mother], the physiotherapist, from the municipality, (nursing) home to see what she needed and which...measures she needed /... / And it took time.

I: Yes. What impact did that cause that it took a long time?

CP:/.../ she stiffened again. For we had been down in the village here training a little getting the joints bent a little. And ... and when it took so long, so ... we felt that she started to tighten up again. What they had managed to loosen up, tightened again.

$/ \ldots /$

I: Yes. Did you send a reminder about it, or ...?

CP: Yes, via home care so ... we told them when they were home, and then ... Yes, would take it further. They would. Noted it down and ...would take it further, but we heard nothing. It didn't come.

According to the care partner, his mother was later first admitted to hospital due to dehydration, then to the mental health hospital for evaluation and finally was admitted to a nursing home for $24 / 7$ care:

I: But then... just that I feel has taken some time. It [physiotherapy] was supposed to come. Yes, we attended a care partner meeting, she was admitted there [old people's home]. Then we tell them that it would have been nice if some... had come. A...nurse with, what is it called... they have one like psychology nurse, or what it's called, who can come. To evaluate and look at things to be done. I: Yes. While she is at old people's home?

CP: Yes. And we haven't heard anything about that either.

(P4; care partner - son) 
This care partner expressed an overwhelming tiredness with 'the system' and it's inability or will to help the family to take care of his mother. He argued that if help had been offered earlier, and the collaboration between the services had been better, then the story about his mother may have had a different ending.

The lack of acknowledgement from professionals of service users and their care partners experience is well rehearsed in the literature (cf Ahmad et al 2014.) Participants in this research wanted their care needs to be acknowledged and followed through. In addition they wanted their perspectives to be recognised and respected as legitimate expressions of need, as illustrated by the following quote for a service user talking about her friend:

SU: Yes the home care nurses were there, you know, frequently there and gave her tablets anyway. However, I suppose there was nothing more. That's what they do.

I: And then maybe it's not so easy to discover that someone really bothers with their nerves? SU: No. However, she was very troubled, she was. She cried and cried and cried ...

[B15; service user - woman]

And another service user describes how his expressions of need based on many years of experience of living with mental illness went unheard:

SU: So I was scared. Sort of. I got anxiety. And then ... yes. I came in, I came in to (psychiatric hospital) then, via my GP, and was admitted ... and so I guess I was a little unfortunate, then, that ... yeah, I do not know if I can say, but ... I did not get any kind of ... confidence in the doctor there. I: No?

SU: ... He did not get my confidence. So I did not believe in what he was doing. He put me on a remedy that I hadn't heard about at all, even though I started back in -88 with antidepressants, so I've been along for quite a while [small laughter] through time and so ... yes. This I was supposed to 
use then, and it had a side effect, and it was that I lost some sleep, and I didn't tolerate it. Didn't cope with losing sleep. Cause' I was fantasizing at night. So I was struggling and was completely exhausted in the morning. And then ... I was supposed to go on with it anyway [laughs a little] ...

$$
\text { [B7; service user - man] }
$$

The service user tells how he was subsequently admitted to an 'in-patient and treatment' center, where the tablets were discontinued: 'Everything that he had put me on'.

The idea that older people and their care partners engage as partners in care is largely not borne out by our data. Despite the rhetoric of collaboration and cooperation, for the majority of participants in this research, this was not their experience and indeed, one interviewee highlighted the problematic nature of the language of collaboration and cooperation when asked how she experienced these processes - "No!! Do I have to take responsibility for that as well?!"

It would be easy to consider these findings in the context of 'ageism' and ageist attitudes among healthcare workers. As one care partner said: 'We got more help when she [his wife] was younger. But... I hadn't imagined that it would turn out like this now, you know, ... [sighs] Just an injection, and then that's it'. However, most of the participants in this study didn't express a sense that they were discriminated against because of their age. Yet, we observed a "redefining" of mental health needs as 'normal and natural ageing' and thus not an issue for treatment (as with younger people with the same issues, e.g. depression). What is more evident however is the lack of recognition among healthcare staff of the role that older people living with mental health problems and their care partners play in managing their social situation, the complexity of which is illustrated by the following data extract: 
I became like this after I lost my son [long pause] ... and from the first 14 days I do not remember anything. After a while I was a little back and forth to work, and then I got a psychologist and I saw him/... / I thought it was a waste of time really, /... / he (the son) disappeared one evening and was found dead half a year later. / ... / When they found him/... / I was on sick leave. /... / I stayed with my friend those fourteen days. And then the crisis team came. And that was very good. /... / I was on sick leave one year and became more and more introverted, / ... / I could always go with contractual pension. / ... / my work has been very important to me. So then I started a little over twenty percent job. / ... / (Went up to) twenty, forty and sixty / ... / percent. And then, I contacted the pension fund of the county council . /... / And I applied for $40 \%$ pension and $60 \%$ job, and that's what I go on now ... / ... / Meanwhile the crisis team made sure I came into the municipal system in relation to Mental Health on health house for talks. It has been there for many months, I think/... / (They) asked if I wanted to join a course called Coping with Anxiety. And that course made my turning point. It was really good.

[B4; service user - man]

In this extract, the extent to which this service user plays an active role in managing his own changed situation and balancing his need to work with self-managing his illness is evident. Managers, leaders and decision-makers viewed the challenges of providing adequate support to older people and their care partners as being associated with macro structures and processes in the health and welfare system, such as municipal budgets assigned from central government and national welfare policies. However, whilst many of the participants also 'blamed' the system for the challenges the nurses faced in doing their job ("they are doing the best they can. They have too many persons on their list") these macro structures and processes were not of immediate concern for them. Mainly their focus was on the quality of interaction they had with those healthcare and welfare workers with whom they came into contact: 
SU: The municipality had grabbed all that ... now I guess they can't take any more ... Bloody municipality shit! Now I swear, because now ...

I: It's quite all right.

SU: Now I'm grumpy ... [so] pissed off with those municipality people that I would have liked to... taken and thrown! I don't know what to ...

I: No. Is it because they decide so much? [long pause]. Is it like you feel that they decide that the home care nurses are in a hurry?

SU: Yes / ... /they decide everything!

I: Do you sometimes talk about your troubles with those that you have a good contact with from the Home Care? ... No?

SU: They do not understand that I suffer (...) talk with the young nurses, they understand. But the old ones, the bitches (a bit too strong a word) they don't understand a shit. They don't understand that I am in pain'.

[B11; service user - woman]

The emotional engagement in this data and from other research participants is obvious and directs the intensity and focus of their engagement in interactions.

\section{The 'Prestige Hierarchy' of Mental Illness in Older People}

In addition to the challenges associated with recognition and acknowledgement that older people and their care partners experience, we also identified the issue of 'prestige' as a barrier to cooperation and collaboration. In the analysis of the data, we identified a common 'thread' running through the collective data set - that of the mental ill-health of the participants not being taken seriously by the municipal health care system or going seemingly unrecognised by nurses and care workers. 
Many of the participants in our study experienced ongoing and significant symptoms of mental illness, including loss of confidence to deal with activities of daily living following a period of depression (B4; service user - man) “... but I think it has a little to do with you yourself, how open you are and how much you demand and ... " I, I got the letter from the home care ... that I still claim the benefit of their service because I have been misdiagnosed and a bit of everything, so they come in the morning and evening ..." (B8; service user - woman); feeling worried about ability to cope with everyday living but afraid to ask for help due to discontinuities in care workers "Anyway, I'm like this, that I have to know a person well before I can sort of talk about things ..." (B16; service user - woman).;

However, for two care partners in particular, their mental health was significantly impacted by their unmet needs. In the case of B2 who is the main carer for his wife and mother-in-law, his loss of relationship with his wife because of the ever-presence of his mother-in-law and increased social isolation significantly impacted on his mental health:

"... she (mother in-law) gets a bit grumpy, you know. And that ... and then her hearing is bad, you know, so its hard to communicate with her. It is very difficult. I can see R (wife) trying and trying and has to, and repeat and repeat and then her voice is almost gone (his wife suffers with COPD) you know. So I do not know if there is anything more to get done with her (mother-in-law) ears ... I think this is the worst because I have, I sometimes say something (to her), but mostly she doesn't hear what I say, so then I don't say so much (laughter)" (P3; care partner - man)

This care partner had home care services coming to their house each morning and evening to help his wife and mother-in-law, but from the data, it appeared that their focus on particular care tasks prevented them from seeing the precarious nature of the home set-up, the total care situation and the needs of the care partner in this situation. Indeed, the care partner was 
puzzled at the lack of recognition of his wife's mental health needs by the municipal health care system for many years:

"Yeah, it's really weird then, for there was, they've viewed like that on the nerves and stuff, so she's been using pills so and so for many years, I think. So, as it were they should have known that there was something. ... could have said that one could try to have conversations with, like yes, psychiatric health services, or that it may be psychologically or whatever the reason may be. It is, it is so. For ... no I do not understand" (P3; care partner - man)

In a similar case, a care partner found himself increasingly isolated by the lack of joined-up thinking by professionals across the care system. His mother whom he cared for got increasingly mentally and physically disabled. She became increasingly dependent on him to meet her care needs, showed signs of anxiety and paranoia and isolated herself from the wider community:

"And then she starts not to go to the store ... / ... / stops being with her sister and her mother, shopping for they have one day a week . / ... / Doesn't go across the street visiting the neighbor anymore. Does not take part in (social life). / ... / This is, of course, going on for a little too long. As it is. And then nothing happens until this spring ... (P4; care partner - man)

His mother had taken to sleeping on the sofa and despite his (and his brother's) efforts she would not sleep in her bed:

"Eh ... If you sit here and you sit with the door open, and she had, say... Yes, can we not close the door? /... / We sat on the veranda. On the veranda and ... and if we go into the living room and sit down in the living room, then she wondered if we could close the door. Why? ... No, someone could come and take her. I have three children. So we were five, and my brother's home. Then no one 
would come and take her. But ... I almost said ... She reads about this woman ... This assault, wasn't that in Bergen. /... / It could happen to her and /... / And then she is sitting like this. That is, at the tip of chair. Sitting here ... Sat there for almost ... a year." (P4; care partner - man)

Whilst the home care services were increased to help with her care needs, there continued to be a lack of recognition of the mental health needs of the service user, the care partner and the wider-family network of support.

\section{DISCUSSION}

Person-centred practices depend on a 'meeting of equals' (McCormack and McCance 2010) in a space that respects the beliefs, values and perspectives of all those involved in care decisions. Similarly in this context, collaboration is critical to the planning of successful care programmes for people living with long-term conditions (Coulter et al 2013). Whilst some participants in this research were reticent about being partners in care, partnership is seen as the cornerstone of good mental health care (Wallcraft 2011) and the essence of mental health recovery (Davidson et al 2012). However, the challenges associated with professionals not moving from a dominant professional hierarchical mode to one of facilitator of decision-making is a key reason for poor cooperation and collaboration (Martin and Finn 2011). In a systematic review of shared decision-making in mental health services, Duncan et al (2010) found no benefits (or harms) to service users through partnering with health and social care professionals in decision-making. Our findings seem to suggest that the 'position' of older people as partners in decision-making has an effect on their ability to engage in partnership working. Collins (2004) argues that this kind of situation is not predicated on the individual's ability to cope but instead starts from the 'situation' in which the individual finds him or herself.

The interaction situations in which professionals and service users take part illustrate what Collins (2004) describes as 'interaction ritual chains' (IRC): 
"A theory of interaction ritual (IR) and interaction ritual chains is above all a theory of situations. It is a theory of momentary encounters among human bodies charged up with emotions and consciousness because they have gone through chains of previous encounters" (Collins 2004: 3).

Interaction ritual chains depend on four criteria - (i) Two or more persons have to be physically on the same spot and in bodily proximity to each other; (ii) those who participate in the ritual need to have a common understanding of who is in the ritual through the work that they are doing; (iii) those who are taking part in the ritual have to have their attention on the same thing - object or action; (iv) all participants have to have a common perception of the atmosphere in the situation. If these four criteria are present in an interaction, then it is possible that it is going to be a situation where emotional energy is loaded up between the persons involved. In these situations, the persons are moved by each other. Interaction situations are seen as rituals, and actions that successfully generate emotions that charge up persons (Collins 2004, 44). Even a very short gesture can have something ritual in it but the ritual aspect will fall away if one or several criteria are absent, e.g. if the interactions are emotionally empty or if people don't direct their attention towards the same focus. According to Collins, IRC is a theory about how human beings go from one situation to another and seek emotional energy (EE). In doing this, the 'chains' of interaction situations are created.

Many of the participants in our research talked about situations that were the opposite of these four criteria. Whilst they were in the same room as the care provider (criterion 1), they only partially had their attention on the same thing (service user concerned about emotional issues, care provider concerned with tasks) and so there was little opportunity for emotional energy to be charged in both participants and so for example, the service users viewed the care provider as 'uncaring'. Such situations may illustrate what Collins (p.53) refers to as forced rituals, where participants act as if the interaction is a ritual according to the four criteria in spite of the fact that some or all 4 of them are missing. Our analysis suggests that for the service user, the 
absence of EE can result in them becoming more passive, disengaged and experiencing what Collins (Collins 2004: 53) refers to as 'interaction fatigue', causing withdrawal and loss of hope reinforcing rather than relieving their mental ill-health. The interaction fatigue that they demonstrate because of the effort needed to fight for what they need is also evident. Thus, the expectation that service users and their care partners can rely on individual agency to engage in cooperative and collaborative relationships with healthcare and welfare workers is unrealistic. It could be implied from our data that the fatigue experienced is a consequence of particular discontinuities - such as discontinuities in relationships due to inconsistent assignment of nurses and care workers, situational discontinuities because of task oriented approaches to care delivery and a lack of cooperation in individual situations because of the situational reality of service users not being treated seriously.

For the nurses and care workers in this research, the way in which their work was organised (lists of task-related visits) provided little opportunity for them to engage emotionally. Intense interaction ritual can be a very powerful experience in a person's life as these can be touching moments that we don't forget too easily and that give meaning to a person's biography (Collins $2004,43)$. What we are touched by we have a tendency to seek again and again and in this way the emotionally loaded interactions we participate in became part of our narratives and what we are not touched by passes away without sticking with us (Skatvedt et al 2015; Skatvedt \& Costain Schou 2008).

Seen from this perspective, for many of the participants in this study, it was the culmination of different situations that created chains of connection that influenced how they self-managed their mental health and in how they related with the healthcare and welfare workers. This culminated experience formed an impression in their minds that the nurses and care workers 'didn't care about them' and contributed to interaction fatigue. As Goffman (1982) argued, it is 
the dynamics of situations that is the appropriate place to start in understanding individuals and how they move across situations:

"A situation is not merely the result of the individual who comes into it, nor even a combination of individuals (although it is that too). Situations have laws or processes of their own; and that is what IR theory is about" (Collins 2004: 5).

Thus Goffman argues that we should pay less attention to individual behaviour in a given situation, but instead we should focus on the effect of the given situation on individual behaviour and individual self-perception.

The concept of prestige was first coined by Max Weber (2010) in his analysis of social status and social ranking of different individuals and groups. Prestige refers to 'status' or 'position' and denotes a hierarchy of acceptability, regard or esteem. Significant work has been undertaken in the field of 'occupational prestige' (cf Ollivier 2000) to demonstrate why some employment routes are afforded greater esteem than others, as is well played out in the 'whitecollar versus blue-collar' classification of work.

More recently, the concept of prestige has been applied to medical practices. In their review of the literature, Norredam and Album (2007) identified that non-specialised, non-high technological types of medicine practised on organs in the lower part of the bodies of older people were accorded low levels of prestige. The authors concluded that differences in prestige of diseases and medical specialties have consequences for healthcare prioritisation and planning. In a further cross-sectional survey of physicians and medical students in Norway (Album and Westin 2008), the researchers identified that "diseases and specialties associated with technologically sophisticated, immediate and invasive procedures in vital organs located in the upper parts of the body are given high prestige scores, especially where the typical patient is 
young or middle-aged" (p182). Of the thirty-eight diseases studied, depressive neurosis, schizophrenia and anxiety neurosis were in the five most lowly ranked diseases and of twentythree medical specialties, psychiatry ranked at twenty and geriatrics the lowest at twenty-three. Thus, older people living with a mental health problem are ranked lowest in every aspect of their condition and the services they are dependent upon. Whilst some studies have been undertaken in nursing that focus on occupational prestige (Treiman 1977; Shortell 1974; Seago 2006) no studies have been undertaken regarding the prestige of particular domains of nursing practice, although there is ample anecdotal evidence suggesting that the prestige of nursing domains matches those of medicine as reported by Album and Westin (2008).

Whilst Skatvedt et al (2015) identified an issue of occupational prestige at play between the specialist mental health services teams and the home care teams, the service user/care partner data that we report on here primarily relates to the issue of 'disease prestige'. How was this prestige manifested? The majority of the participants in our study appeared to have their mental health needs classified as 'low-level', meaning that the mental health challenges they experienced were not perceived by the health care system as needing the input of formal/specialist mental health services, but yet the illnesses they lived with (depression, loneliness, anxiety for example) would usually be offered support from specialist services if the person experiencing the illness was in a younger age-bracket - suggesting that these mental health conditions are regarded differently according to the age of the person.

Edland-Gryt and Skatvedt (2013) in their study of 'low-threshold'i services provided to people with addictions and mental health problems identified the different energies needed by service users in order for their voice to be heard. Trust in the system as well as professionals in the system, were critical factors in service users being able to access care needs. However they also identified that service users needed a range of competencies including, how to get care needs registered as 'a need', how to voice needs and how to 'work' the system in order for care needs 
to be met, e.g. respond to care or treatment in a 'proper' way. In other words: be a successful client/patient. Whilst a different context, the issues raised by Edland-Gryt and Skatvedt (2013) resonate with the experiences of the service users and their care partners in our study. Of particular significance is an observation by Edland-Gryt and Skatvedt concerning the welfare system - they note that a need will only be met when it becomes a 'demand'. However, for the majority of the participants in our research, they had limited ability to transfer their felt-need into a demand for care and treatment. This situation, coupled with what has been described as 'age discrimination in mental health services' (Department of Health [England] 2009) meant that their care needs were unmet.

This finding is particularly significant in the context of collaboration and cooperation reform of services in order to make them more person-centred, as it is consistent with the findings of Laird et al (2015) who identified the vulnerable situation of service-users at the juncture of care systems, care processes and care workers responses. It directs attention towards system-level changes such as community education, awareness raising and support programmes in order to enable older people with mental health problems and their care partners to access the kinds of services they need. However it also raises significant issues about how mental health services are organised and the divide between specialist mental health services and the day-to-day home care services provided by non-specialist care workers. It is clear from our data that the existence of the 'prestige hierarchy' results in a range of actual mental health needs going unnoticed, unacknowledged and unmet.

The low prestige of mental health and ageing as evidenced in our findings also reinforces the need for older people and their care partners to have high levels of competence in having their voices heard. The voicelessness of mental health service users has been identified in previous research (Byrne et al 2013) and a vibrant community of activists have emerged ensuring that people living with mental health problems have a greater chance of having their needs met in 
ways that are respectful, caring, dignified and compassionate. Further, Davidson et al (2012) with a focus on mental health recovery has demonstrated how recovery in mental health is dependent on recognition by all health services of the agency of survivors of mental illness to recover, engage in self-care and regain the capacity to live fulfilled lives. However, there does not appear to be the same focus on agency among older people living with mental health problems and there has been little research undertaken to understand mental health recovery from the perspective of older people - thus reinforcing the low prestige of mental illness in older age.

Considering collaboration and cooperation by older people and their care partners with health services, from the perspectives of Interaction Ritual Chains and Threshold Theory highlights the challenges associated with developing person-centred approaches in health systems. Nurses and care workers strive to work within systems that are designed to deliver essential care to people in greatest need and to do so in a way that maximises efficiency and effectiveness. However, for older people and their care partners, the discontinuities in the systems that they experience in their everyday interactions with nurses and care workers means they don't experience care to be person-centred, i.e. focused on their unique needs. Older people with mental health needs and their care partners need high levels of energy to express these needs and have them met in a way that reflects principles of partnership working. This seems like a significant challenge at a time when they are most vulnerable and in need of greatest support from the health system.

\section{CONCLUSIONS}

If older people with mental health problems and care partners are to engage in collaboration and cooperation with the healthcare and welfare systems, then strategies that empower them to do so are needed. Whilst structural reform of services may result in a more joined up service from an efficiency perspective, it does little to help with the engagement of service users and 
care partners with care providers, as there is 'no point in trying' due to a lack of emotional energy. Much more local work is needed with communities to develop processes of engagement, community education, information sources and facilitators who can work with service users and care partners to help them turn their care needs into demands. The goal of person centred care demands an anchoring in the organisation as a whole. Further, there is a need for the designers of health care systems to recognise that care providers need to work in ways that enable them to expend emotional energy in order to provide high quality personcentred care.

\section{IMPLICATIONS FOR PRACTICE}

Older people with mental health needs living at home are a particularly vulnerable population, as are their care partners. Discontinuities in service delivery models mean that often there is a primary focus on achieving nursing and care tasks within short time-frames. Nurses and care workers need to pay attention to the emotional engagement with older people that is needed in order to help them cope with their day to day life situation.

\section{ACKNOWLEDGEMENTS}

The authors wish to acknowledge the contributions of all those who gave so freely of their time to participate in this research. We also wish to acknowledge Dr David Banks and Professor Jan Dewing, Queen Margaret University, for their feedback on earlier drafts of this manuscript.

\section{FUNDING}

The research reported here was part of a larger project - 'Collaborative practices with older people living at home with mental health problems: A person-centred approach', funded by the Norwegian Research Council. Project number 213296. The funders have played no part in the design, execution, analysis and interpretation of data, or writing of the study. 


\section{CONTRIBUTIONS}

Study Design: BMC; Data collection and analysis: BMC and AS; Manuscript Preparation: BMC and AS.

\section{REFERENCES}

Ahmad N, Ellins J, Krelle H and Lawrie M (2014) Person-centred care: from ideas to action. The Health Foundation, London.

Album D and Westin S (2008) Do diseases have a prestige hierarchy? A survey among physicians and medical students, Social Science and Medicine, 66: 182-188

Biong, S., \& Svensson, T. (2009). Bridging the gaps: Experiencing and preventing life-threatening heroin overdoses in men in Oslo. Int J of Qualitative Studies on Health and Well-being, 4, 94-105.

Borg, M., Karlsson, B. \& Kim, H.S. (2009). User involvement in community mental health services-principles and practices. Journal of Psychiatric and Mental Health Nursing, 16, 3, 285292.

Borg, M, Karlsson, B., Tandora, J. \& Davidson. L. (2009) Person-centred practices in psychiatric rehabilitation-what does this mean. The Israel Journal of Psychiatry and Other Sciences, 46, 2, 84-93.

Byrne L, Happell B, Welch T and Moxham LJ (2013) 'Things you can't learn from books': Teaching recovery from a lived experience perspective. International Journal of Mental Health Nursing, 22, 3, 195-204 
Collins, R (2004) Interaction Ritual Chains. Princeton University Press, Princeton and Oxford.

Coulter A, Roberts S and Dixon A (2013) Delivering better services for people with long-term conditions - Building the house of care. The Kings Fund, London

Davidson, L., Bellamy, C., Guy, K., \& Miller, R. (2012). Peer support among persons with severe mental illnesses: A review of evidence and experience. World Psychiatry, 11, 2, 123-128.

Department of Health [England] (2009) Improving Access to Psychological Therapies. Older People Positive Practice Guide. Department of Health, London

Duncan E, Best C, Hagen S. (2010) Shared decision making interventions for people with mental health conditions. Cochrane Database of Systematic Reviews, Issue 1. Art. No.: CD007297. DOI: 10.1002/14651858.CD007297.pub2.

Edland-Gryt M and Skatvedt AH (2013) Thresholds in a low-threshold setting: an empirical study of barriers in a centre for people with drug problems and mental health disorders, International Journal of Drug Policy, 24, 3, 257-64

European Pact for Mental health and Well-being, European Commission, 13 June 2008, http://ec.europa.eu/health/ph determinants/life style/mental/index en.htm

Geertz C (1973) The interpretation of cultures: selected essays. New York: Basic Books

Goffman, E. (1982). Interaction Ritual. Essays on Face-to-Face Behaviour. New York: Pantheon Books. 
Helse-og omsorgsdepartementet (2007). Demensplan 2015 "Den gode dagen". Delplan til Omsorgsplan 2015. Oslo: Helse- og omsorgsdepartementet.

Helse- og omsorgsdepartementet (2008-2009). Samhandlingsreformen. Rett behandling-på rett sted-til rett tid. St. meld. Nr. 47. Oslo: Helse- og omsorgsdepartementet.

Hill, L. Roberts, G., Wildgoose, J., Hahn, S., Perkins, R., (2010) Recovery and person- centred care in dementia: common purpose, common practice? Advances in Psychiatric Treatment, 16, 288298.

Kjølseth, I., Ekeberg, Ø., \& Steihaug, S. (2009). "Why do they become vulnerable when faced with the challenge of old age?" Elderly people who committed suicide, described by those who knew them. International Psychogeriatrics, 21, 5, 903-912.

Laird, E., McCance, T., McCormack, B. and Gribben, B. (2015) Patients' experiences of in-hospital care when nursing staff were engaged in a practice development programme to promote person-centredness: A narrative analysis study International Journal of Nursing Studies, 52(9): 1454-1462 http://authors.elsevier.com/sd/article/S0020748915001613

Lenze EJ, Mulsant BH, Shear MK, Dew MA, Miller MD, Pollock BG, Houck P, Tracey B and Reynolds CF (2005) Efficacy and Tolerability of Citalopram in the Treatment of Late-Life Anxiety Disorders: Results From an 8-Week Randomized, Placebo-Controlled Trial, American Journal of Psychiatry, 162, 146-150

Lightbody, C.E., Baldwin, R., Connolly, M., Gibbon, B., Jawaid, N., Leathley, M. Et al. (2007). Can nurses help identify patients with depression following stroke? A pilot study using two methods of detection. Journal of Advanced Nursing, 57, 5, 505-512. 
Martin GP and Finn R (2011) Patients as team members: opportunities, challenges and paradoxes of including patients in multi-professional healthcare teams, Sociology of Health and Illness, 33, 7, 1050-1065

McCormack, B. \& McCance, T. (2010). Person-centred Nursing: Theory, models and methods. Blackwell Publishing, Oxford.

McCormack, B., McCarthy, G., Wright, J., Slater, P., \& Coffey, A. (2009). Development and testing of the context assessment index. Worldviews on Evidence Based Nursing, 6, 1, 27-35.

McCormack, B., Karlsson, B., Dewing, J. \& Lerdal, A. (2010). Exploring person-centredness: a qualitative meta-synthesis of four studies and their contribution to advancing our understanding of person-centred nursing, Scandinavian Journal of Caring Sciences, 24, 620-634.

Napier AD, Ancarno C, Butler B, Calabrese J, Chater A, Chatterjee H et al (2014) Culture and Health - The Lancet Commissions. The Lancet, 384, 1607-1639

Norwegian Research Council (2009) Evaluation of the National Programme for Mental Health (2001-2009). Oslo : Norwegian Research Council.

Ollivier M (2000) “Too Much Money Off Other People’s Backs”: Status in Late Modern Societies, Canadian Journal of Sociology 25, 4 (Fall 2000), 441-70

Patton, M (1990) Qualitative evaluation and research methods. Sage., Beverly Hills, CA.

Seago JA, Spetz J, Alvarado A, Keane D and Grumbach K (2006) The Nursing Shortage: Is It Really About Image? Journal of Healthcare Management 51, 2 (Mar/Apr 2006), 96-108. 
Shortell, SM (1974) Occupational prestige differences within the medical and allied health professions. Soc. Sci.Med 8, 1, 1-9

Skatvedt, A., Andvig, E., \& Baklien, B. (2015). Home Service's encounter with the elderly with mental health problems. Nordic Journal of Health Research, 11, 1, 20-34

Skatvedt, A., \& Costain Schou, K. (2008). The beautiful in the commonplace. European journal of cultural studies, 11, 1, 83-100. doi: DOI: 10.1177/1367549407084965

Strong, T., Sutherland, O., \& Ness, O. (2011). Considertations for a discourse of collaboration in councelling. Asia Pacific Journal of Councelling and Psychotherapy, 2, 1, 25-40.

Treiman, DJ (1977) Occupational Prestige in Comparative Perspective. Academic Press, New York.

Wallcraft J, Amering M, Freidin J, Davar B, Froggatt D, Jafri H, Javed A, Katontoka S, Raja S, Rataemane S, Steffen S, Tyano S, Underhill C, Wahlberg H, Warner R and Herrman H (2011) Partnerships for better mental health worldwide: WPA recommendations on best practices in working with service users and family carers. World Psychiatry, 10, 3, 229-236

Weber, M (2010) The Distribution of Power within the Community: Classes, Stände, Parties. Translated by Dagmar Waters,Tony Waters, Elisabeth Hahnke, Maren Lippke, Eva LudwigGlück, Daniel Mai, Nina Ritzi-Messner, Christina Veldhoen and Lucas Fassnacht. Journal of Classical Sociology, 10, 2, 137-152

World Health Organization (2015 i) 2014 WHO Mental Health Atlas. WHO Press, Geneva

${ }^{i}$ The idea of low-threshold has emerged particularly in the field of addictions. It is a term associated with harm reduction, whereby easy access to services that do not require layers of multi-professional referrals, results in more easily accessed help and thus avoiding harm. The term easily translates into services for 
older people and people living with mental health problems as it is well recognized that the provision of low-threshold services (such as home help, handy-person services, day care, sitting and visiting services etc) can prevent deterioration in health status and demands on more specialist/expensive services. 